\title{
DERLEME
}

DOI: $10.4274 /$ nts.galenos.2020.006

Nucl Med Semin 2020;6:28-38

\section{Ağrı Palyasyonunda Yeni Radyonüklidler}

New Radionuclides in Pain Palliation

\section{Umut Elboğa}

Gaziantep Üniversitesi Tıp Fakültesi, Şahinbey Araştırma ve Uygulama Hastanesi, Nükleer Tıp Anabilim Dalı, Gaziantep, Türkiye

\begin{abstract}
Öz
İleri evre kanserli hastalarda iskelet sistemi en yaygın metastaz bölgesidir. Kemik metastazı olan vakalarda ağrı önemli bir sağlık sorunudur. İleri evre kanserli hastalarda kemik metastazına bağlı kemik ağrısını tedavi etmek için kemiğe özgül birikim gösteren radyonüklidler ile tedavi seçili kanserli hasta gruplarında kullanılabilmektedir. Bu derlemede stronsiyum-89, samaryum-153 lexidronam, fosfor-32 sodyum fosfat, lutesyum-177 etilen diamin tetrametilen fosfonik asid gibi beta yayıc radyonüklidler ve alfa yayıcı Radium-223 kullanarak kemik metastazlarının radyonüklid tedavisi için aday hasta gruplarının özellikleri, radyonüklid tedavilerin nasıl yapıldığı ve sonrasında tedavi yanıtları ile yan etkileri değerlendirilecektir.

Anahtar Kelimeler: Radyonüklid tedavi, kemik metastazları, beta yayıcı radyonüklidler, alfa yayıcı radyonüklid
\end{abstract}

\begin{abstract}
Skeletal system is the most common metastasis site in patients with advanced cancer. Pain is an important health problem in patients with bone metastasis. Bone seeking radionuclides to treat bone pain due to bone metastasis in patients with advanced stage cancer can be used in selected group of cancer patients. In this review, evaluating patients who might be candidates for radionuclide treatment of bone metastases using beta-emitting radionuclides such as strontium-89, samarium-153 lexidronam, phosphor-32 sodium phosphate, Lutetium-177 ethylenediaminetetramethylene phosphonic acid and alfa-emmiting Radium-223, performing the treatments; and understanding and evaluating the treatment outcome and side effects.

Keywords: Radionuclide therapy, bone metastases, betaemitting radionuclides, alfa-emitting radionuclide
\end{abstract}

\section{Giriş}

Metastatik kemik hastalığı, ileri evre kanserlerde yaygın ve ciddi bir komplikasyondur. Metastatik kemik hastalığının \%80'i meme, prostat ve akciğer kanserleri ile birliktedir (1). Kemik metastazı olan hastalarda ağrı en önemli sağlık sorunu olarak karşımıza çıkmaktadır. Metastatik hastaların \%90'ında kansere bağlı ağrı bildirilmiştir ve bunların çoğunda kemik ağrısı görülmektedir (2,3). Omurga, pelvis ve kaburgalar en sık metastaz bölgeleridir. Kemik metastazlarının \%80'den fazlası aksiyel iskelet sisteminde yer alır (4).

Kansere bağlı kemik ağrısının tedavisinde non-steroid analjeziklerden opioidlere dek uzanan geniş analjezik ilaç seçenekleri söz konusudur. Analjezik ilaç tedavisi sıklıkla radyoterapi, cerrahi, kemoterapi, hormon tedavisi, bifosfonatlar ve radyonüklid tedavi ile kombine edilebilir. $\mathrm{Bu}$ derlemede bahsedeceğimiz stronsiyum-89 (Sr-89), samaryum-153 (Sm-153), fosfor-32 (P-32), lutesyum-177 (Lu-177) gibi beta ışını yayıcı radyonüklidler ve alfa yayıcı radyum-223 (Ra-223) ile metastatik kemik ağrısı tedavisinin en önemli avantajları şunlardır: Birden fazla hastalık bölgesine ulaşılabilmekte, uygulanması kolay, tekrarlanabilirliği ve diğer tedavilerle eşzamanlı olarak entegre edilebilmesi mümkün tedavi seçeneğidir. Alfa ışını yayan radyonüklidlerle yapılan tedavilerde (örneğin Ra-223) ise metastaza bağlı ağrıyı tedavi etmenin yanı

\section{Yazışma Adresi/Address for Correspondence}

Doç. Dr. Umut Elboğa, Gaziantep Üniversitesi Tıp Fakültesi, Şahinbey Araştırma ve Uygulama Hastanesi, Nükleer Tıp Anabilim Dalı, Gaziantep, Türkiye E-posta: umutelboga@hotmail.com ORCID ID: orcid.org/0000-0002-3650-8258

${ }^{\circledR}$ Telif Hakkı 2020 Türkiye Nükleer Tıp Derneği / Nükleer Tıp Seminerleri, Galenos Yayınevi tarafından yayınlanmıştır. 
sıra aynı zamanda hastanın yaşam süresinin uzadığı da gösterilmiştir (5). Ra-223, beta ışını yayıcılardan farklı fiziksel ve klinik özelliklere sahip alfa ışını yayıcı bir radyonükliddir. Ra-223 metastatik kastrasyona dirençli prostat kanserinde (mCRPC), bilinen visseral organ metastazı olmayan hastalarda semptomatik kemik metastazları için endikedir (6). Bu derlemede ağrı palyasyonunda kullanılan eski radyonüklid tedavilerin tedavi sonuçları ve yan etki profillerinin yanısıra yeni uygulanan radyonüklid tedavilerde literatür bilgileri ışı̆̆ında değerlendirilecektir. Bu derlemede kaynak olarak başta 2018 yılında güncellenen Avrupa Nükleer Tıp Derneği'nin beta ışını yayıcılarla kemik metastazlarının radyonüklid tedavisi rehberi olmak üzere 1993-2019 yılları arasında yayınlanmış Sr-89, Sm-153, Re-188, P-32, Lu-177 ve Ra-223 ile radyonüklid tedavide özellikle ağrı yanıtı, analjezik ihtiyacı, yan etkiler ve yaşam sürelerinin değerlendirildiği makaleler incelendi. Sr-89 ve Sm-153 ile ilgili etkin bazı çalışmalar Tablo 1'de özetlenmiştir (7-30).

\section{Etki Mekanizması}

Metastatik kemik hastalığı için kullanılan radyonüklidlerle yapılan tedavilerde osteoblastik aktivite artışı gözlenen metastatik tümoral odaklar olması gereklidir. Bu durumda radyonüklidin metastaz odaklarında selektif ve uzamış tutulumu sözkonusu olabilmekte ve etkinlik bu şekilde elde edilmektedir. Radyonüklid tedavilerin tam olarak etki mekanizması açıklanamamakla birlikte öne sürülen bir takım hipotezler mevcuttur. Normal kemik dokusu ile kemik tümörü arasındaki yüzeyde bulunan enflamatuvar hücrelerce üretilen ağrı mediyatörlerinin (örneğin histamin, prostaglandin $E$, interlökin, lökotrienler veya $\mathrm{P}$ maddesi) radyonüklid tedavi sonrası düşüş gösterdiği ileri sürülen hipotezlerden biri, radyasyonun etkisi ile ağrıdan sorumlu olabilecek mekanik faktörlerden periosteal şişmede azalma sağlanabildiği de ileri sürülen hipotezlerden bir diğeridir (31). Kemik metastazları osteoblastların hareketi nedeniyle skleroz veya sklerotik metastazlar olarak gözlenebilir, iskelet sisteminde osteoblastların hareketi fokal olarak artmış metabolik aktivite reaksiyonu yaratır, kemik sintigrafisinde bu durum artmış tutulum olarak tanımlanır. Osteoklastların hareketinin neden olduğu kemik yıkımı alanları osteolitik kemik metastazları olarak gözlenebilir. Miks tarz denilen osteoblastik ve osteolitik metastazın birlikteliği de birçok lezyonda yaygındır (32).

\section{Klinik Endikasyonlar}

- Tüm vücut kemik sintigrafisi ile yoğun tutulum gösteren osteoblastik metastaz odaklarının ağıı palyasyonu,

- Tüm vücut kemik sintigrafisinde osteoblastik yanıtı olan ve ağrılı seyreden primer kemik tümörlerinde kullanılabileceği belirtilmektedir. Bu endikasyon henüz onaylanmamıştır.

- Alfa ışını yayıcı Ra-223 ile semptomatik kemik metastazı tedavisi ise bilinen metastatik visseral hastalığı olmayan metastatik kastrasyon dirençli prostat kanseri hastalarında endikedir. Ra-223, bu endikasyonun hedeflendiği ilk alfa tedavisidir ve yeni bir tedavi seçeneği sunar. Bu endikasyonda alfa yayıcıların hem genel sağkalıma hem de iskelete bağıı semptomatik olayın geç ortaya çıkması açısından önemli bir fayda sunduğuna dair prospektif randominize kontrollü çalışma ile gösterilmiş kanit mevcuttur(6).

\section{Kontraendikasyonlar}

Mutlak kontrendikasyonlar hamilelik ve emzirmedir. Rölatif kontrendikasyon ise azalmış kemik iliği rezervidir. Önceden sitotoksik kemoterapi ve/veya radyasyon tedavisi (eksternal beam radyasyon tedavisi) alan veya kemiğin ileri yaygın metastatik infiltrasyonu ile riskli kemik iliği rezervi olan hastalarda nötropeni ve trombositopeni gibi risklere yönelik klinik risk-fayda değerlendirmesi yapılır ve sonrasında tedavi verilebilir. Bu hastalarda yakın izlem gerekir. Genellikle tüm vücut kemik sintigrafisinde superscan görünümü, kemik iliği tutulumunun önemli bir göstergesidir ve olası yan etkiler nedeniyle bu durumda radyonüklid tedaviler kontrendikedir. Belli sınırlar içinde nispeten düşük kan hücresi sayımları myelotoksisite riski nedeniyle radyonüklid tedavisi için rölatif kontraendikasyon kabul edilebilir. Bununla birlikte kesin alt sınır literatürde iyi tanımlanmamıştır ve granülosit koloni uyarıcı faktörlerin kullanımı limiti daha da azaltabilir. Rutin olarak, aşağıdaki değerler uygulanabilir $(20,33,34,35)$.

1. Hemoglobin $<9 \mathrm{~g} / \mathrm{L}$,

2. Toplam beyaz kan hücre sayısı $<3,5 \times 10^{9} / \mathrm{L}$

3. Trombosit sayısı $<100 \times 10^{9} /$ L. Yaygın intravasküler koagülasyon (DIC) tedavisinden sonra ciddi trombositopeni riski olabileceğinden, subklinik DIC olan hastaları belirlemek için pıhtılaşma faktörlerine yönelik testler çalışılmalıdır (36).

Kemik iliği tutulumunun varlığı, kan değerlerinin belirtilen sınırlar içinde kalması ve myelotoksisitenin beklenen eşiği geçmemesi durumunda bir kontrendikasyon oluşturmaz. 
Umut Elboğa. Ağrı Palyasyonunda Nükleer Tıp

Tablo 1. Geçmiş yıllarda yayınlanmış stronsiyum-89 ve samaryum-153 ile ilgili etkin çalışmaların özeti

\begin{tabular}{|c|c|c|c|c|c|c|c|c|c|}
\hline & Referans & YIl & Çalışma tipi & \begin{tabular}{|l|} 
Hasta \\
sayısı
\end{tabular} & Doz (SI) & Kanser & $\begin{array}{l}\text { Ağrı } \\
\text { cevabı \% }\end{array}$ & $\begin{array}{l}\text { Analjezik } \\
\text { azaltma }\end{array}$ & Cevap süresi \\
\hline \multirow[t]{9}{*}{ 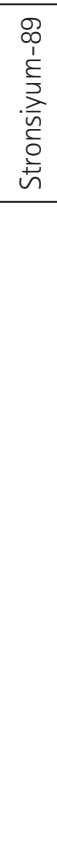 } & Fuster et al. (9) & 2000 & Tek merkez, I-II & 40 & $4 \mathrm{mCi}(148 \mathrm{MBq})$ & Meme & 92 & Bilinmiyor & $120 \pm 143$ gün \\
\hline & $\begin{array}{l}\text { Kraeber-Bodere et } \\
\text { al. (10) } \\
\end{array}$ & 2000 & $\begin{array}{l}\text { Tek merkez, } \\
\text { retrospektif }\end{array}$ & 94 & $4 \mathrm{mCi}(150 \mathrm{MBq})$ & Prostat & 78 & $\% 60$ & Bilinmiyor \\
\hline & Turner et al. (11) & 2001 & Tek merkez, II & 93 & $4 \mathrm{mCi}(150 \mathrm{MBq})$ & Prostat & 63 & Bilinmiyor & Bilinmiyor \\
\hline & Dafermou et al. (12) & 2001 & Çok merkez III & 527 & $4 \mathrm{mCi}(148 \mathrm{MBq})$ & Prostat & 59,8 & Evet & $5,0 \pm 3,5$ ay \\
\hline & Ashayeri et al. (13) & 2002 & $\begin{array}{l}\text { Tek merkez, I-II, } \\
\text { retrospektif }\end{array}$ & 27 & $4 \mathrm{mCi}(150 \mathrm{MBq})$ & Prostat ve meme & 81 & Evet & Bilinmiyor \\
\hline & Zorga et al. (14) & 2003 & Tek merkez, I-II & 33 & $4 \mathrm{mCi}(148 \mathrm{MBq})$ & $\begin{array}{l}\text { Prostat, meme, } \\
\text { mesane ve renal } \\
\text { hücreli }\end{array}$ & 82 & Evet & Bilinmiyor \\
\hline & Baczyk et al. (15) & 2003 & Tek merkez, II & 70 & $4 \mathrm{mCi}(148 \mathrm{MBq})$ & Prostat & 88 & 50 & Bilinmiyor \\
\hline & $\begin{array}{l}\text { Gunawardana et al. } \\
\text { (17) }\end{array}$ & 2004 & Tek merkez, I-II & 13 & $4 \mathrm{mCi}(148 \mathrm{MBq})$ & Prostat & 57 & Evet & 56 gün \\
\hline & Liepe K et al. (18) & 2007 & Tek merkez, I-II & 15 & $4 \mathrm{mCi}(148 \mathrm{MBq})$ & Prostat ve meme & 72 & Evet & Bilinmiyor \\
\hline \multirow[t]{12}{*}{ 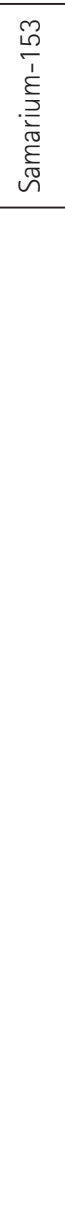 } & Collins et al. (20) & 1993 & Tek merkez, I-II & 52 & $\begin{array}{l}0,5-3 \mathrm{mCi} / \mathrm{kg} \\
(18,5-111 \mathrm{MBq} / \\
\mathrm{kg})\end{array}$ & Prostat & 75 & Evet & $\begin{array}{l}\text { Ortalama süre } \\
2,6 \text { aydı }\end{array}$ \\
\hline & Serafini et al. (21) & 1998 & Tek merkez, II-III & 118 & \begin{tabular}{|l|}
$0,5-1 \mathrm{mCi} / \mathrm{kg}$ \\
$(18,5-37 \mathrm{MBq} / \mathrm{kg})$ \\
\end{tabular} & $\begin{array}{l}\text { Prostat, meme, } \\
\text { diğerleri }\end{array}$ & $62-72$ & Evet & $\begin{array}{l}\text { Hastaların \%43'ünde } \\
\text { 16. haftaya kadar } \\
\end{array}$ \\
\hline & Tian et al. (22) & 1999 & Çok merkez, II-III & 105 & $\begin{array}{l}1 \mathrm{mCi} / \mathrm{kg}(37 \\
\mathrm{MBq} / \mathrm{kg})\end{array}$ & $\begin{array}{l}\text { Prostat, meme, } \\
\text { diğerleri }\end{array}$ & 84 & 87,5 & Bilinmiyor \\
\hline & Dolezal et al. (23) & 2000 & Tek merkez, I-II & 33 & $\begin{array}{l}1 \mathrm{mCi} / \mathrm{kg}(37 \\
\mathrm{MBq} / \mathrm{kg})\end{array}$ & $\begin{array}{l}\text { Prostat, meme, } \\
\text { diğerleri }\end{array}$ & 71 & Evet & Bilinmiyor \\
\hline & Wang et al. (24) & 2003 & Tek merkez, I-II & 9 & $\begin{array}{l}1 \mathrm{mCi} / \mathrm{kg}(37 \\
\mathrm{MBq} / \mathrm{kg})\end{array}$ & $\begin{array}{l}\text { Prostat, meme, } \\
\text { diğerleri }\end{array}$ & 78 & Bilinmiyor & $\begin{array}{l}\text { Ağrıda azalma } \\
\text { genellikle } 3 \text { haftadan } \\
\text { fazlaydı }\end{array}$ \\
\hline & Sapienza et al. (25) & 2004 & $\begin{array}{l}\text { Tek merkez, II, } \\
\text { retrospektif }\end{array}$ & 73 & \begin{tabular}{|l|}
$1 \mathrm{mCi} / \mathrm{kg}(37$ \\
$\mathrm{MBq} / \mathrm{kg})$ \\
\end{tabular} & Prostat, meme & 76 & Bilinmiyor & Bilinmiyor \\
\hline & $\begin{array}{l}\text { Etchebehere et al. } \\
(26)\end{array}$ & 2004 & $\begin{array}{l}\text { Tek merkez, II, } \\
\text { retrospektif }\end{array}$ & 58 & $\begin{array}{l}1.0-1.6 \mathrm{mCi} / \mathrm{kg} \\
(37-59.2 \mathrm{MBq} / \\
\mathrm{kg})\end{array}$ & $\begin{array}{l}\text { Prostat, meme, } \\
\text { diğerleri }\end{array}$ & 78 & Bilinmiyor & Bilinmiyor \\
\hline & Sartor et al. (27) & 2004 & $\begin{array}{l}\text { Çok merkez } \\
\text { III, prospektif, } \\
\text { randomize, çift- } \\
\text { kör }\end{array}$ & 152 & $\begin{array}{l}1 \mathrm{mCi} / \mathrm{kg}(37 \\
\mathrm{MBq} / \mathrm{kg})\end{array}$ & Prostat & 65 & Evet & Bilinmiyor \\
\hline & Tripathi et al. (28) & 2006 & Single-centre, II & 86 & $\begin{array}{l}1 \mathrm{mCi} / \mathrm{kg}(37 \\
\mathrm{MBq} / \mathrm{kg})\end{array}$ & $\begin{array}{l}\text { Prostat, meme, } \\
\text { diğerleri }\end{array}$ & 73 & Evet & $\begin{array}{l}16 \text { hafta boyunca } \\
\text { düzenli olarak yapıldı }\end{array}$ \\
\hline & Ripamonti et al. (29) & 2007 & \begin{tabular}{|l|} 
Pilot çalışmal \\
Olgu serisi
\end{tabular} & 13 & \begin{tabular}{|l}
$1 \mathrm{mCi} / \mathrm{kg}(40$ \\
$\mathrm{MBq} / \mathrm{kg})$ \\
\end{tabular} & Prostat & 61,50 & Evet & 4 haftadan daha fazla \\
\hline & Liepe K et al. (18) & 2007 & Tek merkez, I-II & 15 & $\begin{array}{l}1 \mathrm{mCi} / \mathrm{kg}(37 \\
\mathrm{MBq} / \mathrm{kg})\end{array}$ & Prostat ve meme & 73 & Evet & Bilinmiyor \\
\hline & Olea et al. (30) & 1996 & Tek merkez, I-II & 40 & $\begin{array}{l}1,0-1,5 \mathrm{mCi} / \mathrm{kg} \\
(37-55 \mathrm{MBq} / \mathrm{kg})\end{array}$ & $\begin{array}{l}\text { Prostat, meme, } \\
\text { diğerleri }\end{array}$ & 67,5 & Bilinmiyor & Bilinmiyor \\
\hline
\end{tabular}


Umut Elboğa. Ağrı Palyasyonunda Nükleer Tıp

\begin{tabular}{|c|c|c|c|}
\hline Yan etkiler & Flare fenomeni & $\begin{array}{l}\text { Objektif cevap } \\
\text { kriteri }\end{array}$ & Yorumlar \\
\hline Lökosit ve trombosit sayısında geçici ve hafif düşme & Bilinmiyor & Bilinmiyor & Tedavi güvenle aynı etkinlikte tekrar edilebilir \\
\hline \%5 olguda yüksek dereceli lökotrombositopeni & $\% 23$ & Bilinmiyor & $\begin{array}{l}\text { Hastaların 3/4'ünde ikinci doz sonrası toksisite } \\
\text { artışı olmaksızın analjeziyi devam edebiliyor }\end{array}$ \\
\hline Bilinmiyor & Bilinmiyor & Bilinmiyor & $\begin{array}{l}\text { PSA, tedavi sonucu için yararlı bir gösterge } \\
\text { olamadı }\end{array}$ \\
\hline Hematolojik toksisite (hafif ve orta)- $\% 25,5$ & $\% 14,1$ & Bilinmiyor & $\begin{array}{l}\text { Tekrarlayan tedavilerde başarı ilk tedaviye } \\
\text { nazaran anlamlı derecede kötü } \\
\end{array}$ \\
\hline Bilinmiyor & Bilinmiyor & Bilinmiyor & Hayır \\
\hline Geçici hematotoksisite- \%48 & Bilinmiyor & Bilinmiyor & $\begin{array}{l}\text { Tedavi sonrası ortalama yaşam süresi } 21 \text { ila } 138 \\
\text { hafta arasında (ortalama } 58 \text { hafta) }\end{array}$ \\
\hline Bilinmiyor & Bilinmiyor & Bilinmiyor & $\begin{array}{l}\text { Motor aktivite, yaşam kalitesi ve Karnofsky } \\
\text { skoru anlamlı derecede düzeldi }\end{array}$ \\
\hline $\begin{array}{l}\text { Olguların tamamında trombositopeni, genelinde ise } \\
\text { hafif lökopeni vardı }\end{array}$ & Bilinmiyor & Bilinmiyor & $\begin{array}{l}\text { Kemoterapi refrakter prostat kanserinde uzun } \\
\text { süreli hematolojik parametrelerin izlenmesi } \\
\text { gereklidir }\end{array}$ \\
\hline Trombositopeni genellikle grade 1 & Bilinmiyor & Bilinmiyor & $\begin{array}{l}\text { Trombosit ve lökosit sayımlarının en düşük } \\
\text { değeri tedaviden sonra } 2 \text {. ila } 5 \text {. hafta arasında } \\
\text { gözlendi ve } 12 \text { hafta içinde eski haline geldi }\end{array}$ \\
\hline $\begin{array}{l}\text { Toksisite en yüksek doz alanlarda hematolojikti, bu } \\
\text { grubunda \%86'sı iyileşme gösterdi }\end{array}$ & Bilinmiyor & $\begin{array}{l}\text { Daha yüksek doz alan } \\
\text { hastalarda sağkalımın } \\
\text { uzadığına dair trend } \\
\text { gözlendi }\end{array}$ & $\begin{array}{l}\text { Daha yüksek doz alan hastalarda PSA } \\
\text { seviyesinde anlamlı azalmalar gözlendi }\end{array}$ \\
\hline $\begin{array}{l}\text { Kemik iliği supresyonu hafif, geri dönüşümlü ve Grade } \\
\text { IV toksisite ile ilişkili değildi }\end{array}$ & Bilinmiyor & Bilinmiyor & e \\
\hline $\begin{array}{l}\text { Kemik iliği supresyonu hafif, geri dönüşümlü ve grade } \\
\text { IV toksisite ile ilişkili değildi }\end{array}$ & Bilinmiyor & Bilinmiyor & $\begin{array}{l}\text { Sadece meme kanseri olan hastalarda } \\
\text { Karnofsky skorunda anlamlı bir değişiklik } \\
\text { gözlendi }\end{array}$ \\
\hline Bilinmiyor & Bilinmiyor & Bilinmiyor & - \\
\hline $\begin{array}{l}\text { Kemik iliği süpresyonu hafif, geri dönüşümlü ve grade } \\
\text { IV toksisite ile ilişkili değildi }\end{array}$ & Bilinmiyor & Bilinmiyor & - \\
\hline $\begin{array}{l}\text { Hafif ila orta şiddette myelosupresyon \%75,3 } \\
\text { oranında saptandı, } 8 \text { haftada düzelme oldu }\end{array}$ & Bilinmiyor & Bilinmiyor & - \\
\hline Önemli myelotoksisite gözlenmedi & Bilinmiyor & Bilinmiyor & - \\
\hline $\begin{array}{l}\text { Tedaviden } 3 \text { ila } 4 \text { hafta sonra hafif, geçici kemik iliği } \\
\text { baskılanması, tedaviden } 8 \text { hafta sonra yan etkide } \\
\text { iyileşme }\end{array}$ & Bilinmiyor & Bilinmiyor & - \\
\hline $\begin{array}{l}\text { Hafif, geçici kemik iliği baskılanması tedaviden sonra } \\
\text { tek yan etki, 6-8 hafta sonra iyileşme }\end{array}$ & Bilinmiyor & Bilinmiyor & - \\
\hline $\begin{array}{l}3 \text { hastada hafif ve kolayca geri çevrilebilir kemik iliği } \\
\text { baskılanması }\end{array}$ & Bilinmiyor & Bilinmiyor & - \\
\hline Genellikle grade 1 trombositopeni & Bilinmiyor & Bilinmiyor & $\begin{array}{l}\text { Trombosit ve lökosit sayımlarının en düşük } \\
\text { değeri tedaviden sonra } 2 \text {. ila } 5 \text {. haftalar } \\
\text { arasında gözlendi ve } 12 \text { hafta içinde geri } \\
\text { çevrilebildi }\end{array}$ \\
\hline Kemik iliği baskılanması \%37 hastada saptandı & Bilinmiyor & Bilinmiyor & 17 hastada birden fazla tedavi uygulandı \\
\hline
\end{tabular}


Kan hücre sayımları, kemik ağrısı palyasyon tedavisi yapılmadan önce stabil olmalıdır. Düşük kan hücresi sayımları nedeniyle tedavinin uygulanmasında herhangi bir şüphe veya gecikme olursa, tedaviden hemen önce kan hücre sayımlarının tekrarlanması kan tablosunda oluşabilecek hızlı bir bozulmayı öngörmek için gereklidir.

Böbrek fonskiyon kusuru durumunda varlığı durumunda kemik ağrısı palyasyon tedavisinde kullanılan beta yayıcı radyofarmasötiklerin plazma klirensi azalır ve daha yüksek bir tüm vücut dozu ve daha yüksek myelotoksisite riski ile karşı karşıya kalınır. Bu nedenle, ciddi şekilde böbrek fonksiyonu azalmış olan hastalarda, yani kreatinin $>180$ umol/L ve/veya glomerüler filtrasyon hızı $<30 \mathrm{~mL} /$ dakika ise hasta radyonüklid tedavi programından çıkarılmalıdır.

\section{Yaşam Beklentisi}

Palyatif etkinin başlangıcındaki gecikmeyi (birkaç gün ila 4 hafta) göz önünde bulundurarak, radyonüklid tedavinin nispeten uzun bir yaşam beklentisi olan ve metastatik kemik hastalığının erken evrelerindeki hastalarda daha yararlı olduğu bildirilmektedir. Sr-89, Sm-153, P-32, Lu-177 veya Ra-223 ile palyatif kemik ağrısı tedavisi, 4 haftadan az bir yaşam beklentisi olan hastalarda uygun değildir. Yaşam beklentisi 6 aydan fazla olarak belirlenmiştir.

\section{Radyonüklid Tedavinin Etkinliği}

\section{Ağrı Kontrolü}

Osteoblastik veya miks paternli (osteoblastik/ osteoklastik) kemik metastazlı hastalarda beta ışını yayıcı radyonüklidler ile palyatif kemik ağrısı tedavisinin yararlı etkisini destekleyen klinik kanıtlar mevcuttur. Klinik çalışmalarda yayınlanan verilerin gözden geçirilmesi ile hastaların yaklaşık \%50-90'ında ağrı cevabının oluştuğu, hatta \%12 ila 33'lük bir hasta grubunda tam ağrı cevabının bile sağlanabileceği gösterilmektedir (7-30). Dokuz randomize klinik çalışma, 13 klinik çalışma ve 35 gözlemsel çalışmayı kapsayan sistemik bir metaanalizde çoğu kemik metastazı olan prostat kanseri hastaları değerlendirilmiştir (37). Bu meta analize göre Sm-153, Lu-177 veya Sr-89 ile tek bir radyonüklid tedavi sonrası hastaların \%70'inde ağrının azaltılmasının sağlandığına dair kanıtlar mevcut olup, diğer ağrı tedavileri ile kombinasyon yapılması durumunda ağrı azalması \%74 oranında gerçekleşmiştir. Bu metaanalize göre prostat kanseri olan hastalarda ağrı azalması \%70, meme kanseri olan hastalarda \%79'lardaydı. Bu sonuçlar temel olarak iki farklı meta analiz ile de doğrulanmıştır
$(38,39)$. Finlay ve ark. (35) sistematik derlemelerinde beta yayıcı radyonüklid tedavinilerin etkinliğini şu şekilde belirtiyorlar: Hastaların \%32'sinde (\%8-77) tam semptomatik yanıtın gösterildiği, hastaların \%44'ünde kısmi yanıtın gösterildiği, \%25'inde (\%14-52) ise ağrı palyasyonunun sağlanamadığı belirtilmedktedir (35). Radyonüklid tedavi sonrası analjezik kullanımının \%7181 oranında azaldığı anlaşılmaktadır. Radyonüklid tedavinin analjezik etkileri tedavi başlangıcından 4-28 gün sonra gözlenmişti ve tedavi yanıt süresi 15 aya kadar uzayabilmişti. Christensen ve Petersen çalışmalarında kemik metastazlı meme kanseri hastalarında beta yayıcı radyonüklid tedavinin etkinliğine dair güvenilir kanıtın mevcut olduğunu bildirmişlerdi (40). Bu çalışmalar ışığında beta ışını yayıcı radyonüklid tedavi, osteoblastik veya karışık paternli (osteoblastik/osteoklastik) özellikleri olan ağrıı kemik metastazları olan hastalarda palyatif tedavi olarak önerilebilir. Ek olarak bir alfa yayıcı radyonüklid olan Ra-223 ile kemik metastazı olan CRPC hastalarında yapılan ve 4 farklı doz düzeyi uygulanan (5 kBq/kg, $25 \mathrm{kBq} / \mathrm{kg}, 50 \mathrm{kBq} / \mathrm{kg}, 100 \mathrm{kBq} / \mathrm{kg}$ ) bir faz 2 çalışmasında ikinci haftada her dozda analjezik yanıt görülmekle birlikte sadece en yüksek dozda ALP düzeyinde düşüşe eşlik eden anti-tümör etkiler izlenmiştir (41).

\section{Yaşam Kalitesi}

Birkaç çalışma, ağrılı kemik metastazları için beta yayıcı radyonüklid tedaviden sonra yaşam kalitesinin arttı̆̆ını göstermiştir $(15,42,43)$. Radyonüklid tedavi osteoblastik veya karışık paternli (osteoblastik/osteoklastik) kemik metastazları olan hastalarda yaşam kalitesini artırmak için tavsiye edilebilir.

\section{Sağkalım}

Sr-89, Sm-153, P-32 veya Lu-177 gibi beta yayıcı radyonüklidlerle tedaviden sonra sağkalım yararlarını araştıran hiçbir çalışma yoktur. Bununla birlikte, prostat kanserinde yapılan bir faz 2 çalışmasında, Sr-89'a kemoterapi (doksorubisin) eklendiğinde $(27,7$ aya karşı 16,8 ay) bir sağkalım yararı görülmüştür (44). Diğer yandan, Ra-223 ile yapılan çalışmalarda metastatik CRPC'li visseral yayılım olmaksızın kemik metastazı olan hastalarda genel sağkalımı 3,6 ay artırdığı, ilk iskelet ilişkili olayın 5,8 ay geciktirdiği gösterilmiş ve ALSYMPCA (Alpharadin in Symptomatic Prostate Cancer) çalışmasında ölüm riskinin \%30 azaldığı tespit edilmiştir $(5,41)$. Diğer terapötik radyonüklidlerin genel sağkalımı artırdığına dair faz 3 çalışması ile klinik kanıt yoktur. 


\section{Yan Etkiler}

"Flare" fenomeni ağrı semptomlarında artışı ifade eder. Genellikle tedavinin başlatılmasından 72 saat sonra ortaya çıkar ve hastaların yaklaşık \%10'unda görülür. Hastaların çoğunda hafif ve sınırlıdır, genellikle standart analjeziklere yanıt verir. Genel olarak, "flare" fenomeni iyi bir klinik yanıtla ilişkilidir $(35,45,46)$. Servikodorsal spinal metastazların varlığı, spinal kord kompresyonu riskinin artmasıyla ilişkili olabilir. Bu durumda profilaktik kortikosteroidler düşünülebilir ve tedavi öncesi spinal MRG ve/veya nörolojik konsültasyon önerilir.

Myelosupresyonun bir sonucu olarak periferik kanda trombosit ve lökosit sayısındaki azalmalar sıklıkla gözlenir. Bu yan etki Sm-153 için 3-5 haftada, Lu-177 için 2-4 haftada, Sr-89 ve P-32 için 12-16 haftada görülür. Grade 3 veya 4 toksisitesinin ortaya çıkması, hastanın önceden myelosupresif tedavi alıp almadığına ve kemik iliği rezervine bağlıdır. Hematolojik toksisite genellikle 3 ay içinde tamamen iyileşme ile geçici olarak gözlenebilir. Periyodik hematolojik izleme, tedaviden sonra 6. haftaya kadar (Sm-153 ve Lu-177 için) yüksek riskli hastalarda anlamlı myelosupresyonun önlenmesi için yararlı olabilir. Sr-89 ve P-32 ile tedaviden sonra, uzamış miyelosupresif toksisite (12-16 hafta) nedeniyle daha uzun takip gereklidir (47). Kısa etki menzili sayesinde hedef dışı dokulardaki toksisitesi az olan Ra-223'ün, yapılan bir faz III çalışmasında karşılaştırmalı gruplarda hematolojik yan etki sıklığı ile anlamlı bir ilişkisi olmadığı ortaya konulmuştur (5).

\section{Ağrı Palyasyonunda Beta Yayıcı Yeni Radyonüklid: Lu-177 EDTMP Tedavisi}

Lu-177 orta enerjili beta-radyasyonu oluşturan radyonüklidlerden olmaka beraber malign tümörlerin selektif yıkımında başarılıdır. Lu-177'nin orta düzeyli beta-enerjisinin yanısıra (497 keV: \%78,6; $384 \mathrm{keV:}$ $\% 9,1 ; 176 \mathrm{keV} \% 12,2)$ düşük enerjili iki gama emisyonu da (208 keV: \%11; 113 keV: \%6,6) bulunmaktadır. Bu gama emisyonu aracılığıyla radyonüklid bileşiğin vücuttaki dağılımı sintigrafi ile takip edilebilir. Avantajlı bozunum spektrumu sayesinde Lu-177, hem tedavi hem de tanı amaçlı kullanılabilen radyonüklidlere örnek teşkil etmektedir (48). Lu-177'nin diğer beta emisyonu yapan radyonüklidlerden farklı olarak orta düzey enerji oluşturması düşük yan etki potansiyeli açısından ön plana çıkmaktadır.

Radyonüklidler ile kararlı kompleksler oluşturduğundan fosfonat bazlı bir ajan olan etilen diamin tetrametilen fosfonik asid (EDTMP), ağrılı kemik metastazı olan hastaların internal radyoterapisinde ligand olarak kullanılabilmektedir. EDTMP ile oluşturulan komplekslerin biyodistribüsyon çalışmalarında kemik dokuya yüksek oranda geçebildiği gösterilmiştir. Bunun yanında EDTMP'nin osteoblastik kemik metastazlarına da yüksek afinitesi mevcuttur (49). Lu177-EDTMP kompleksinin bütün hastalarda izlenen iyi kemik retansiyonunun yanında IV enjeksiyonu takiben 4. saat itibarıyla kemik dışı dokularda aktivite tutulumu saptanmamış olup radyofarmasötiğin çoğunluğunun renal yolla elimine edildiği ortaya konulmuştur (49).

Yuan ve ark. kemik metastazı olan meme kanseri ve CRPC olan 16 hasta ile yürüttüğü faz II çalışmasında tedavi yanıtı vizüel ağrı skorlaması (VAS), Karnofsky indeksi ve Analjezik Kullanım skorlaması ile değerlendirilmiş olup hastaların 8'i meme kanseri 8'i ise prostat kanseri olan hastalardan oluşmaktadır (50). Hastalar, düşük doz grubu ve yüksek doz grubu olarak sekizer kişilik gruplara ayrılmış sırasıyla ortalama $1290 \mathrm{MBq}$ ve 2626,4 MBq dozlarında tedavi almışlardır. Hastalar tedavi sonrası 2., 4., 6., 8. ve 12. haftalarda değerlendirilmiş olup her iki grupta da ağrı yanıtı alınmış ve yaşam kalitesinde artış izlenmiştir. İkinci haftada hastaların \%91'inde ağrı yanıtı alınmaya başlanmış ve 6 . haftada tüm hastaların \%62,5'inde ağrı yanıtı gözlenmiştir. Doza göre yapılan değerlendirmede $1290 \mathrm{MBq}$ sabit doz ile tedavi edilen 1. grubun \%55'inde; $2626,4 \mathrm{MBq}$ sabit doz ile tedavi edilen 2. grubun \%80'inde komplet ağrı yanıtı gözlenmiştir. Analjezik kullanan 5 hastadan dördü 4. hafta itibari ile analjezik kullanmayı bırakmış bir hasta da 2-12 haftalar arasında kullanılan analjezik dozunda düşüş tespit edilmiştir. Altıncı haftanın sonunda her iki grupta da ağrı yanıtı izlenmesine karşın iki grup arasında Bazal Ağrı skorlarına göre doza bağlı anlamlı bir fark tespit edilememiştir. Karnofsky skorlarında her iki grupta da olumlu yanıt alınmış ağrı yanıtına paralellik gözlenmiştir. Kemikiliği depresyonu bağlamında 2. hafta itibariyle hasta gruplarında hemoglobin, platelet ve lökosit sayımlarında düşüş izlenmiş 4-8 haftalar arasında maksimum seviyeye ulaşmış ve 12 . haftada tekrardan düzeldiği izlenmiştir. Bununla birlikte kan sayımında her iki doz grubu arasında anlamlı bir fark tespit edilememiştir. Lu177-EDTMP tedavisinin kemik metastazı olan meme kanseri ve CRPC hastaları üzerine palyatif etkisi ortaya konulan çalışmada bu etkinin 3 aydan daha fazla sebat ettiği belirtilmiştir.

\section{Ağrı Palyasyonunda Alfa Yayıcı Yeni Radyonüklid: Ra-223 Diklorid}

Farklı bozunum karakteristiği ile ön plana çıkan Ra223, kemik metastazı olan CRPC hastalarında aktif kemik turnover alanlarına alfa partikül radyasyonu aracılığı ile 
etki gösteren bir kalsiyum mimetiktir (Şekil 1). Kalsiyummimetik özelliği sayesinde kemik mineral dokusu ile kompleks oluşturur ve $\% 25^{\prime} i$ kemik metabolizmasına paralel olarak iskelet sisteminde tutulur (51). Ra-223 özellikle osteoblastların mikro çevresinde veya sklerotik metastaz alanlarında yeni oluşturulan kemik stromal alanlarına bağlanarak etki eder. Bir alfa yayıcı izotop olan Ra-223 oldukça yüksek lineer enerji transferi (LET) sayesinde $(80 \mathrm{keV} / \mu \mathrm{m})$ hücre DNA'sında çift zincir kırıklarına yol açarak hücre içi apopitozisi başlatmaktadır (52). Alfa partiküllerin doku içerisinde gidebildiği mesafe çok kısa olduğundan (2-10 hücre), Ra-223 uygulaması sonrasında kemik iliği gibi diğer normal organlara önemli bir zarar vermez. Tedavi dozlarında enjekte edilen Ra223 'ün yaklaşık olarak \%25'i kemikler tarafından tutulur ve büyük oranda gastrointestinal sistem tarafından atılır. Yirmi dört saat sonrasında enjekte edilen miktarın \%1'inden azı kanda bulunmaktadır (51). Yapılan dozimetrik çalışmalarda, terapötik doz (70 kg'lik bir hasta için $50 \mathrm{kBq} / \mathrm{kg}^{\prime}$ den 6 siklus Ra-223 enjeksiyon) sonrasında en yüksek doza kemik endosteumu (16 Gy) maruz kalırken kemik iliğinin maruz kaldığı doz değeri 1,6 Gy olarak bulunmuştur (53). Ra-223'ün radyobiyolojik etkileri esas olarak alfa partikülleri ile tümör hücresinin DNA'sında çift sarmal kırıklarına yol açarak onarılamayacak hasarlar meydana getirmesidir. Yüksek LET sayesinde, alfa partikülleri dezentegrasyon alanında yoğun iyonizasyona yol açıp oksijen konsantrasyonundan bağımsız sitotoksik etki yaratır (54).

Ra-223, bir prospektif, uluslararası, randomize, çift kör ve plasebo grubu ile karşılaştırmalı faz III çalışması olan ALSYMPCA çalışmasının sonuçlarına dayanarak, semptomatik mCRPC ve kemik metastazlı hastalarda kullanılmak üzerine 2013 yılında Amerikan Gıda ve Illaç Dairesi (FDA) onayını almıştır (5). Bu çalışmada mCRPC'li ve kemik metastazlı hastalarda Ra-223'ün etkinliği
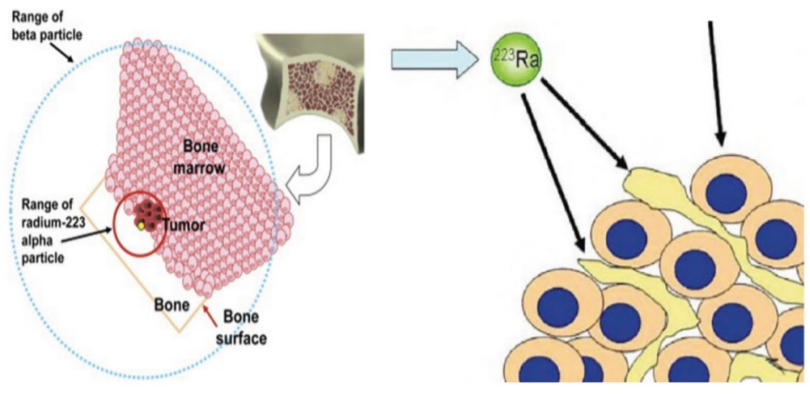

Şekil 1. Radyum-223 periyodik cetvelde kalsiyum ile aynı grupta yer alır ve benzer yapısı ile kemiklerde hidroksi apatit kristallerine bağlanır (5) ve güvenilirliğinin plasebo grubu ile karşılaştırılması amaçlanmıştır. Bu amaçla toplam 921 hasta çalışmaya dahil edilmiş olup bunların 614'üne 4 hafta arayla 50 $\mathrm{kBq} / \mathrm{kg}$ 'den 6 enjeksiyon şeklinde Ra-223 diklorid, 307 'sine de plasebo olarak $\mathrm{NaCl}$ verilerek en iyi bakım şartları sağlanmıştır. Çalışmanın birincil sonlanım noktası genel sağkalım, ikincil sonlanım noktası ise ilk semptomatik iskelet olayı gelişimi ve çeşitli biyokimyasal değişikliklerin ortaya çıkması şeklinde belirlenmiştir. Bu çalışmada tüm hastalar dosetaksel kullanmamışlardır. Çalışma öncesinde dosetaksel kullanmayan hasta oranı \%43'tür. Sadece dosetaksel kullanımı sırasında veya sonrasında progresyon gelişen hastalar dahil edilmiş olup viseral organ metastazı olan hastalar çalışma dışı bırakıımıştır. Çalışmanın sonuçlarına göre, plasebo grubu ile karşılaştırıldığında Ra-223 ile tedavi edilen hastalarda genel sağkalımın uzadığı gösterilmiştir (14,9 aya karşın 11,3 ay; HR: 0,7, \%95 Cl) (Şekil 2). Ölüm riskini \%30 azaltmıştır. Ayrıca Ra-223 ile tedavi edilen hastalarda semptomatik iskelet ilişkili olayların gelişme sürelerinin

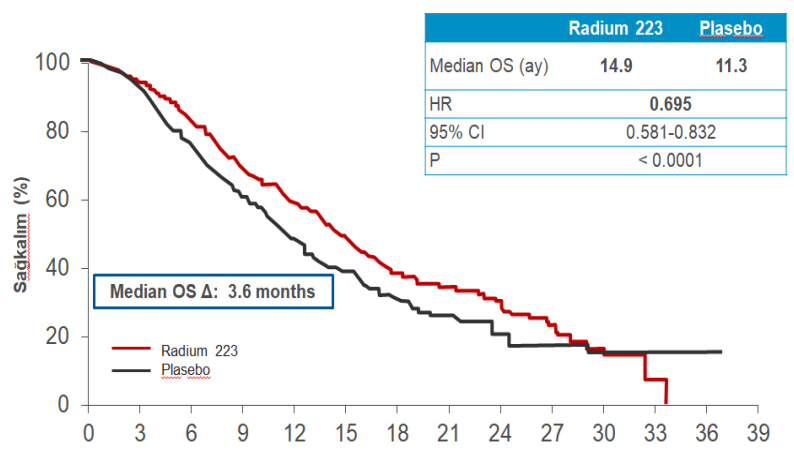

Şekil 2. ALSYMPCA-Plaseboya göre Radyum-223'ün genel sağkalım üstünlüğü (5)

ALSYMPCA: Alpharadin in Symptomatic Prostate Cancer

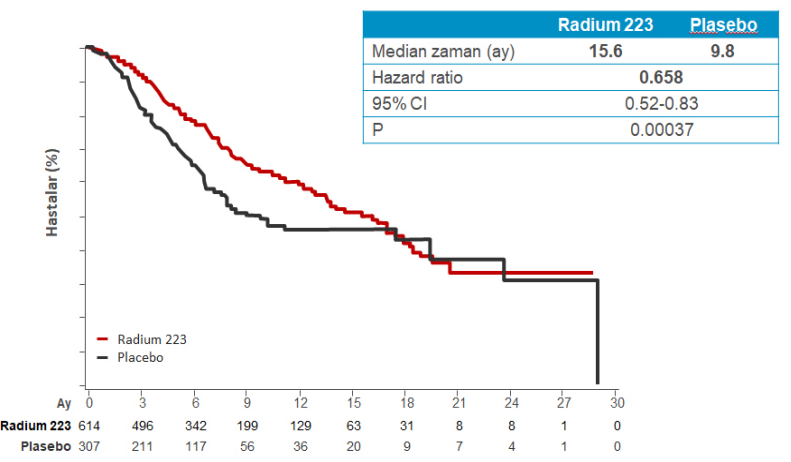

Şekil 3. ALSYMPCA-Radyum-223'ün semptomatik iskelet ile ilişkili olaya kadar geçen sürede plaseboya üstünlüğü (5)

ALSYMPCA: Alpharadin in Symptomatic Prostate Cancer 
uzadığı gözlenmiştir (15,6 aya karşın 9,8 ay; HR: 0,66, \%95 CI) (Şekil3). Ra-223'ün aynızamanda kemikmetastazlarına bağı ağrıda palyatif etkisi olduğu gösterilmiştir. İki grup arasında 3. ve 4. derecede komplikasyon görülme sıklığı arasında anlamlı bir fark izlenmemiştir. Ra-223'ün görülen en sık yan etkisi anemi, trombositopeni ve ishal olmuştur. ALSYMPCA çalışmasının temel limitasyonu Ra-223 tedavisi öncesinde veya eş zamanlı olarak, hastaların abiraterone ve enzalutamid gibi yeni anti hormonal tedavi ajanları ile tedavi edilmemesidir. Diğer bir tek kollu faz-IIlb çalışmasında ise hastalara eş zamanlı yeni anti-tümöral ilaçlar ve hastaların yaklaşık $\% 60$ 'ına öncesinde dosetaksel tedavisi uygulanmıştır. ALSYMPCA çalışmasındakine benzer aktivite miktarlarında Ra-223 4 hafta aralıklarla 6 enjeksiyon yapılmıştır. Çalışmanın sonuçları genel sağkalım süresi 16 ay ile ALSYMPCA'ya benzer bulunmuştur. Genel sağkalım süresi eş zamanlı anti-androjen tedavisi alan grupta anti-androjen tedavisi almayan gruba göre daha uzun bulunmuştur (55). Önceden dosetaksel kullanmış olan veya olmayan mCRPC ve semptomatik kemik metastazlı hastalarda Ra223 'ün etkinlik ve güvenliliği ile ilgili diğer bir alt grup analiz çalışmasında, plasebo ile karşılaştırıldığında Ra223 tedavisi alan hastalarda genel sağkalım dosetaksel kullanımından bağımsız olarak anlamlı derecede uzamıştır. Ra-223'un öncesinde dosetaksel kullanımı dikkate alınmaksızın etkili ve iyi tolere edilebilir ajan olduğu gösterilmiştir (56). Aynı çalışmada semptomatik kemik metastazlı mCRPC'li hastalarda, öncesinde dosetaksel kullananlarda Ra-223'ün, iskelet ile ilişkili semptomatik olayların gelişimine kadar geçen süreyi uzattığı bildirilmektedir. Literatürde ALSYMPCA alt grubu altında yapılan iki çalışmada Ra-223'ün hem genel sağkalım üzerinde hem de kemoterapiye hassas hastaların yaşam kalitesi üzerine faydalı olduğu gösterilmiştir (55-57). Hoskin ve ark. (56) mCRPC'li ve semptomatik kemik metastazlı hastalarda öncesinde dosetaksel kullanımından bağımsız olarak Ra-223'ün genel sağkalımı uzattığını ve iyi tolere edildiğini ortaya koymuşlardır. Benzer şekilde Nilsson ve ark. (57) Ra223'ün hastalıkla ilişkili yaşam kalitesini iyileştirdiğini ve yaşam kalitesindeki düşüşün daha yavaşladığını göstermişlerdir. Günümüzde viseral organ metastazlı hastalarda Ra-223 endikasyonu bulunmamaktadır. Benzer sonuçlar kemik metastazlı ve bilinen organ metastazı olmayan radyum öncesinde dosetaksel tedavisi alan hastalarda da bulunmuştur (52). Sonuç olarak, Ra-223 mCRPC için FDA onayı almış 6 ilaçtan biridir. Günümüzde Ra-223 tedavisi viseral organ metastazı olmayan sadece kemik metastazı olan ve bu metastazlara bağlı yoğun kemik ağrı kliniği olan hastalarda sağkalımı artırmak ve ağrıları azaltmak için kullanılmaktadır. Bu sayede hastaların yaşam kalitesinde belirgin artış görülmektedir. ALSYMPCA çalışmasının sonuçlarından ilham alınarak ilerleyen yıllarda asemptomatik ya da minimal sempomatik hastalar ile yapılacak çalışmalar Ra-223'ün endikasyonlarını genişletecektir. Ra-223 tedavisi 4 hafta ara ile toplam 6 enjeksiyon şeklinde uygulanmaktadır. Tedavinin toksik etkileri hafif derecededir ve genelde tolere edilebilir. Tedavi sonrasında genellikle önemli radyasyon yayınımı olmaz ve hastalar rutin günlük yaşamını sürdürebilmektedir.

\section{Kaynaklar}

1. Coleman RE, Rubens RD. The clinical course of bone metastases from breast cancer. Br J Cancer. 1987;55:61-66.

2. Levy MH. Pharmacologic treatment of cancer pain. N Engl J Med. 1996;335:1124-1132.

3. Mercadante S. Malignant bone pain: pathophysiology and treatment. Pain. 1997;69:1-18.

4. Nielsen OS, Munro AJ, Tannock IF. Bone metastases: pathophysiology and management policy. J Clin Oncol. 1991;9:509-524.

5. Parker C, Nilsson S, Heinrich D, et al. Alpha emitter radium-223 and survival in metastatic prostate cancer. $\mathrm{N}$ Engl J Med. 2013;369:213-223.

6. Poeppel TD, Handkiewicz-Junak D, Andreeff $M$, et al. EANM Guideline for radionuclide therapy with radium-223 of metastatic castration-resistant prostate cancer. Eur J Nucl Med Mol Imaging. 2017;45:824-845.

7. Handkiewicz-Junak D, Poeppel TD, Bodei L. et al. EANM guidelines for radionuclide therapy of bone metastases with beta-emitting radionuclides. Eur J Nucl Med Mol Imaging. 2018;45:846-859.

8. Lewington VJ, McEwan AJ, Ackery DM, et al. A prospective, randomised double-blind crossover study to examine the efficacy of strontium-89 in pain palliation in patients with advanced prostate cancer metastatic to bone. Eur J Cancer. 1991;27:954-958.

9. Fuster D, Herranz D, Vidal-Sicart S, et al. Usefulness of strontium-89 for bone pain palliation in metastatic breast cancer patients. Nucl Med Commun. 2000;21:623-626.

10. Kraeber-Bodéré F, Campion L, Rousseau C, Bourdin S, Chatal $\mathrm{JF}$, Resche I. Treatment of bone metastases of prostate cancer with strontium-89 chloride: efficacy in relation to the degree of bone involvement. Eur J Nucl Med. 2000;27:1487-1493.

11. Turner SL, Gruenewald S, Spry N, Gebski V. Metastron users group. Less pain does equal better quality of life following strontium-89 therapy for metastatic prostate cancer. $\mathrm{Br} \mathrm{J}$ Cancer. 2001;84:297-302. 
12. Dafermou A, Colamussi P, Giganti M, Cittanti C, Bestagno M, Piffanelli A. A multicentre observational study of radionuclide therapy in patients with painful bone metastases of prostate cancer. Eur J Nucl Med. 2001;28:788-798.

13. Ashayeri E, Omogbehin A, Sridhar R, Shankar RA. Strontium 89 in the treatment of pain due to diffuse osseous metastases: a university hospital experience. J Natl Med Assoc. 2002;94:706-711.

14. Zorga P, Birkenfeld B. Strontium-89 in palliative treatement of painfull bone metastases. Ortop Traumatol Rehabil. 2003;5:369-373.

15. Baczyk M, Milecki P, Baczyk E, Sowinski J. The effectiveness of strontium 89 in palliative therapy of painful prostate cancer bone metastases. Ortop Traumatol Rehabil. 2003;5:364-368.

16. Oosterhof GO, Roberts JT, de Reijke TM, et al. Strontium (89) chloride versus palliative local field radiotherapy in patients with hormonal escaped prostate cancer: a phase III study of the European Organisation for Research and Treatment of Cancer, Genitourinary Group. Eur Urol. 2003;44:519-526.

17. Gunawardana DH, Lichtenstein M, Better N, Rosenthal M. Results of strontium-89 therapy in patients with prostate cancer resistant to chemotherapy. Clin Nucl Med. 2004;29:8185.

18. Liepe K, Kotzerke J. A comparative study of 188Re-HEDP, 186Re-HEDP, 153Sm-EDTMP and 89Sr in the treatment of painful skeletal metastases. Nucl Med Commun. 2007;28:623630.

19. Zenda S, Nakagami Y, Toshima M, et al. Strontium-89 (Sr-89) chloride in the treatment of various cancer patients with multiple bone metastases. Int J Clin Oncol. 2014;19:739-743.

20. Collins C, Eary JF, Donaldson G, et al. Samarium-153-EDTMP in bone metastases of hormone refractory prostate carcinoma: a phase I/II trial. J Nucl Med. 1993;34:1839-1844.

21. Serafini AN, Houston SJ, Resche I, et al. Palliation of pain associated with metastatic bone cancer using samarium-153 lexidronam: a double-blind placebo-controlled clinical trial. J Clin Oncol. 1998;16:1574-1581.

22. Tian JH, Zhang JM, Hou QT, et al. Multicentre trial on the efficacy and toxicity of single-dose samarium-153-ethylene diamine tetramethylene phosphonate as a palliative treatment for painful skeletal metastases in China. Eur J Nucl Med. 1999;26:2-7.

23. Dolezal J. Systemic radionuclide therapy with samarium-153EDTMP for painful bone metastases. Nucl Med Rev Cent East Eur. 2000;3:161-163.

24. Wang RF, Zhang CL, Zhu SL, Zhu M. A comparative study of samarium-153-ethylenediaminetetramethylene phosphonic acid with pamidronate disodium in the treatment of patients with painful metastatic bone cancer. Med Princ Pract. 2003;12:97-101.

25. Sapienza MT, Ono CR, Guimarães MI, Watanabe $\mathrm{T}$, Costa PA, Buchpiguel CA. Retrospective evaluation of bone pain palliation after samarium-153-EDTMP therapy. Rev Hosp Clin Fac Med Sao Paulo. 2004;59:321-328.

26. Etchebehere EC, Pereira Neto CA, Lima MC, et al. Treatment of bone pain secondary to metastases using samarium-153EDTMP. Sao Paulo Med J. 2004;122:208-212.

27. Sartor O, Reid RH, Hoskin PJ, et al. Samarium-153-lexidronam complex for treatment of painful bone metastases in hormone-refractory prostate cancer. Urology. 2004;63:940945.

28. Tripathi M, Singhal T, Chandrasekhar N, et al. Samarium-153 ethylenediamine tetramethylene phosphonate therapy for bone pain palliation in skeletal metastases. Indian J Cancer. 2006;43:86-92.

29. Ripamonti C, Fagnoni E, Campa T, Seregni E, Maccauro M, Bombardieri E. Incident pain and analgesic consumption decrease after samarium infusion: a pilot study. Support Care Cancer. 2007;15:339-342.

30. Olea E, Gil MC, Tomicic M, et al. Nationally produced 153SmEDTMP in the palliative treatment of metastatic bone cancer pain. Rev Med Chil. 1996;124:805-812.

31. Krishnamurthy GT, Krishnamurthy S. Radionuclides for metastatic bone pain palliation: a need for rational reevaluation in the new millennium. J Nucl Med. 2000;41:688691.

32. Edwards GK, Santoro J, Taylor AJR. Use of bone scintigraphy to select patients with multiple myeloma for treatment with strontium-89. J Nucl Med. 1994;35:1992-1993.

33. Farhanghi $M$, Holmes RA, Volkert WA, Logan KW, Singh A. Samarium-153-EDTMP: pharmacokinetic, toxicity and pain response using an escalating dose schedule in treatment of metastatic bone cancer. J Nucl Med. 1992;33:1451-1458.

34. De Klerk JM, Zonnenberg BA, Blijham GH, et al. Treatment of metastatic bone pain using the bone seeking radiopharmaceutical re-186-HEDP. Anticancer Res. 1997; 17:1773-1377.

35. Finlay IG, Mason MD, Shelley M. Radioisotopes for the palliation of metastatic bone cancer: a systematic review. Lancet Oncol. 2005;6:392-400.

36. Taylor Jr AJ. Strontium-89 for the palliation of bone pain due to metastatic disease. J Nucl Med. 1994;35:2054.

37. D’Angelo G, Sciuto R, Salvatori M, et al. Targeted "boneseeking" radiopharmaceuticals for palliative treatment of bone metastases: a systematic review and meta-analysis. Q J Nucl Med Mol Imaging. 2012;56:538-543.

38. Roque M, Martinez MJ, Alonso P, Catala E, Garcia JL, Ferrandiz M. Radioisotopes for metastatic bone pain. Cochrane Database Syst Rev. 2003;4:CD003347.

39. Bauman G, Charette M, Reid R, Sathya J. Radiopharmaceuticals for the palliation of painful bone metastasis - a systemic review. Radiother Oncol. 2005;75:258-270.

40. Christensen $\mathrm{MH}$, Petersen LJ. Radionuclide treatment of painful bone metastases in patients with breast cancer: a systematic review. Cancer Treat Rev. 2012;38:164-171. 
41. Nilsson S, Strang P, Aksnes AK, et al. A randomized, doseresponse, multicenter phase II study of radium-223 chloride for the palliation of painful bone metastases in patients with castration-resistant prostate cancer. Eur J Cancer. 2012;48:678-686.

42. Porter AT, McEwan AJ, Powe JE, et al. Results of a randomized phase-III trial to evaluate the efficacy of strontium-89 adjuvant to local field external beam irradiation in the management of endocrine resistant metastatic prostate cancer. Int J Radiat Oncol Biol Phys. 1993;25:805-813.

43. Kurosaka S, Satoh T, Chow E, et al. EORTC QLQ-BM22 and QLQ-C30 quality of life scores in patients with painful bone metastases of prostate cancer treated with strontium-89 radionuclide therapy. Ann Nucl Med. 2012;26:485-491.

44. Tu SM, Millikan RE, Mengistu B, et al. Bone-targeted therapy for advanced androgen-independent carcinoma of the prostate: a randomised phase II trial. Lancet. 2001;357:336341..

45. Resche I, Chatal JF, Pecking A, et al. A dose-controlled study of $153 \mathrm{Sm}$ - ethylenediaminetetramethylenephosphonate (EDTMP) in the treatment of patients with painful bone metastases. Eur J Cancer. 1997;33:1583-1591.

46. Paszkowski AL, Hewitt DJ, Taylor AJR. Disseminated intravascular coagulation in a patient treated with strontium-89 for metastatic carcinoma of the prostate. Clin Nucl Med. 1999;24:852-854.

47. Silberstein EB, Williams C. Strontium-89 therapy for the pain of osseous metastases. J Nucl Med. 1985;26:345-348.

48. Pillai MR, Chakraborty S, Das T, Venkatesh M, Ramamoorthy N. Production logistics of Lu-177 for radionuclide therapy. Appl Radiat Isot. 2003;59:109-118.

49. Chakraborty S, Das T, Banerjee S, et al. Lu-177 EDTMP: a viable bone pain palliative in skeletal metastasis. Cancer Biother Radiopharm. 2008;23:202-213.

50. Yuan J, Liu C, Liu X, et al. Efficacy and safety of Lu-177 EDTMP in bone metastatic pain palliation in breast cancer and hormone refractory prostate cancer: a phase II study. Clin Nucl Med. 2013;38:88-92.

51. Nilsson S, Larsen RH, Foss SD, et al. First clinical experience with $\alpha$-emitting radium-223 in the treatment of skeletal metastases. Clin Cancer Res 2005;11:4451-4459.

52. Ritter MA, Cleaver JE, Tobias CA. High-LET radiations induce a large proportion of non-rejoining DNA breaks. Nature 1977;266:653-655.

53. Lassmann M, Nosske D. Dosimetry of 223Ra-chloride: dose to normal organs and tissues. Eur J Nucl Med Mol Imaging 2013;40:207-212.

54. Bruland OS, Nilsson S, Fisher DR, Larsen RH. High-linear energy transfer irradiation targeted to skeletal metastases by the alpha-emitter 223Ra: adjuvant or alternative to conventional modalities? Clin Cancer Res 2006;12:62506257.

55. Saad F, Carles J, Gillessen S, et al. Radium-223 and concomitant therapies in patients with metastatic castration-resistant prostate cancer: an international, early access, open-label, single-arm phase 3b trial. Lancet Oncol 2016;17:1306-1316.

56. Hoskin P, Sartor O, O'Sullivan JM, et al. Efficacy and safety of radium-223 dichloride in patients with castration-resistant prostate cancer and symptomatic bone metastases, with or without previous dosetaksel use: a prespecified subgroup analysis from the randomised, double-blind, phase 3 ALSYMPCA trial. Lancet Oncol 2014;15:1397-1406.

57. Nilsson S, Cislo P, Sartor O, et al. Patient-reported quality of life analysis of radium-223 dichloride from the phase 3 ALSYMPCA study. Ann Oncol 2016;27:868-874.

58. Sartor O, Hoskin P, Coleman RE, et al. Chemotherapy following radium-223 dichloride treatment in ALSYMPCA. Prostate 2016;76:905-916. 